Check for updates

Cite this: RSC Adv., 2018, 8, 26804

\title{
Decoration of an inorganic layer with nickel (hydr) oxide via green plasma electrolysis
}

\begin{abstract}
Siti Fatimah, ${ }^{a}$ Fitri Khoerunnisab and Young Gun Ko (D) *a
In this study, we describe the green plasma electrolysis of a magnesium alloy in alkaline electrolyte to produce a hybrid inorganic layer with nickel (hydr)oxide incorporated in a matrix of magnesium oxide, and investigate the electrochemical and optical properties of this material. The addition of $\mathrm{Ni}\left(\mathrm{NO}_{3}\right)_{2} \cdot 6 \mathrm{H}_{2} \mathrm{O}$ to the electrolyte reduced the size of the micro-defects found in the inorganic layer after plasma electrolysis by inducing soft plasma discharges. As a result, through cyclic voltammetry and polarization tests, the corrosion stability of the sample containing nickel (hydr)oxide was significantly enhanced. Measurement of the optical properties reveals that the material possesses excellent energy efficiency as indicated by a high solar absorptivity of $\sim 0.92$ and a low infrared emissivity of $\sim 0.13$ which are presumably due to the inherent dark-brown colour of nickel (hydr)oxide. We expect that these results will have implications in the development of functional materials with excellent optical and corrosion properties by considering green processing utilizing alkaline electrolyte.
\end{abstract}

Received 1st June 2018

Accepted 18th July 2018

DOI: $10.1039 / \mathrm{c} 8 \mathrm{ra0} 4708 \mathrm{a}$

rsc.li/rsc-advances

the development of dark-coloured materials suitable for practical applications remains a challenge.

Because of the low thermal emittance of metals, desirable Solar energy is regarded as a promising energy source due to its abundance and renewability. The solar spectrum band covers the wavelengths from 200 to $2500 \mathrm{~nm}$, which correspond to the ultraviolet (UV), visible (Vis) and near infra-red (NIR) bands, while the thermal radiation of an ideal black body is in the range of 2500-25 $000 \mathrm{~nm}$, which corresponds to the mid- and far infra-red bands. ${ }^{1}$ To optimize the absorption of solar radiance, a material must have high solar absorbance $\left(\alpha_{\mathrm{s}}\right)$, low reflectance, and low thermal emittance $(\varepsilon)$ to allow for the effective absorption of solar radiation and the preservation of the heat by suppressing light/infrared re-radiation; that is, its energy efficiency $\left(\alpha_{\mathrm{s}} / \varepsilon\right)$ must be high., ${ }^{2,3}$

Dark-coloured coatings have attracted great interest for applications in solar-absorbance materials, optical equipment, and sensors, and in the aerospace and defence industries. ${ }^{2-4}$ In addition to high absorption capacity, an important strategy for obtaining dark-coloured materials is to incorporate particles or microstructure arrays, which restrict light in deep pores, such as carbon nanotubes. ${ }^{2-4}$ However, two important problems from previous investigations remain unresolved: (1) the produced dark-materials exhibit poor adhesion with substrate, limiting their practical applications; (2) their low reflectance properties are achieved at the expense of large size and low cost. Therefore,

${ }^{a}$ Materials Electrochemistry Group, School of Materials Science and Engineering, Yeungnam University, Gyeongsan 38541, Republic of Korea. E-mail: younggun@ynu. $a c . k r$

${ }^{b}$ Department of Chemistry, Indonesia University of Education, Bandung 40154, Indonesia

substrates with a high thermal conductivity. ${ }^{3}$ Recently, numerous surface treatment technologies have been proposed to prepare coatings with high $\alpha_{\mathrm{s}}$ values on metal substrates, including electroplating, blackening treatment, and plasma electrolytic oxidation..$^{3-5}$ Electroplating and blackening treatments are conventional methods that are commonly used to produce attractive black-coloured coatings. ${ }^{5}$ However, the coatings produced by these methods exhibit several drawbacks, such as non-uniform thickness, low adhesion, insufficient mechanical properties, and inferior corrosion resistance, which limit their applications even in mild environments. Furthermore, the disposal of the liquid waste generated by these methods raises several environmental issues such as acidic and highly oxidative solution. Thus, the development of an ecofriendly, pollution-free processing method to produce protective and high performance coatings is urgently required for a number of industries.

Plasma electrolytic oxidation (PEO) is a green method utilizing one-step electrolysis that allows the fast growth of amorphous/crystalline oxides of the original material on the surface of lightweight metals and their alloys (Al, Mg, Ti) via plasma discharges to produce an adhesive, hard, and corrosionresistant inorganic layer. ${ }^{6}$ The characteristics of the inorganic layer formed by the PEO process are affected by the plasma characteristics (size, density, intensity, and duration), which can be controlled by the electrolyte conditions, e.g. its chemical composition, and the processing variables, such as electrical 
parameters, including current density, frequency, and current mode. ${ }^{7,8}$ Among these, the chemical composition of the electrolyte is believed to be the most important factor in improving the microstructure and functional properties of the inorganic layer. ${ }^{9}$ To date, several studies have proposed the incorporation of colouring agents into inorganic layers to improve their solar absorptivity $\left(\alpha_{\mathrm{s}}\right) \cdot{ }^{10}$ The formation of transition metal oxides as colouring agent during the PEO process, including titanium oxide $\left(\mathrm{TiO}_{2}\right)$, ammonium metavanadate $\left(\mathrm{NH}_{4} \mathrm{VO}_{3}\right)$, copper oxide (CuO), sodium tungstate $\left(\mathrm{Na}_{2} \mathrm{WO}_{4}\right)$, and zinc oxide ( $\left.\mathrm{ZnO}\right)$, has been reported to play a crucial role in improving the absorbance value of the resulting materials. ${ }^{11-14}$ However, those method also have several limitations, such as poor adhesion and nonuniform coating, which limit their application.

Transition metal oxides produces a dark colour on the surface of the inorganic layer, resulting in high light absorption as their solar absorbance $\left(\alpha_{\mathrm{s}}\right)$ value approaches the value of black body $\left(\alpha_{\mathrm{s}}\right.$ $=1)$. The transition metal nickel $(\mathrm{Ni})$ is well-known to be an effective solar absorber material for applications in optical and solar-thermal conversion. ${ }^{5}$ The development of Ni-incorporated inorganic layers has attracted great interest, since such layers exhibit excellent solar absorbance and corrosion resistance. In a report by Somasundaram et al. ${ }^{15}$ the $\alpha_{\mathrm{s}}$ value of an inorganic layer fabricated on a copper substrate was improved by the deposition of $\mathrm{Zn}-\mathrm{Ni}$, due to the formation of a uniform flat-absorbing $\mathrm{Zn}-\mathrm{Ni}$ layer. A similar study was reported by Shashikala et al., ${ }^{16}$ in which a black Ni-cobalt layer was formed on an aluminium substrate by electroplating and exhibited a high $\alpha_{\mathrm{s}}$ value of $\sim 0.94$. These excellent properties were attributed to the formation of $\mathrm{Ni}$ oxides, generating a dark-coloured inorganic layer that provided good corrosion resistance. ${ }^{5}$ Multiple reduction-oxidation (redox) processes occur during the electrodeposition of $\mathrm{Ni}$, leading an inorganic layer with a complex composition containing Ni-oxides with several oxidation numbers. ${ }^{17}$ Unfortunately, these strategies require several processing steps and have a high cost due to the utilization of $\mathrm{Ni}$ and its alloys as the parent materials to produce the dark-coloured inorganic layer. Previous investigation reported that incorporation of $\mathrm{Ni}$ ions on $\mathrm{TiO}_{2}$ matrix could enhanced the catalytic and photocatalytic properties of $\mathrm{TiO}_{2}$ films. ${ }^{18,19}$ However, the studies reporting the incorporation of nickel ions into the matrix of $\mathrm{MgO}$ via $\mathrm{PEO}$ are limited. Although prior study by Hwang et $a .^{20}$ reported the effect of $\mathrm{Ni}$ ions to the colour and microhardness of resultant coating, the incorporation mechanism, and the functional properties of $\mathrm{Ni}-\mathrm{MgO}$ composites grown by plasma electrolysis have never been discussed before.

Here, we investigate the facile fabrication of a high absorbance hybrid layer with corrosion resistant properties through a one-step processing method by adding a simple $\mathrm{Ni}$ salt, $\mathrm{NiNO}_{3} \cdot 6 \mathrm{H}_{2} \mathrm{O}$, to the alkaline electrolyte to decorate a highly adhesive inorganic layer via PEO. The solar absorptivity of the samples was evaluated by measuring the absorbance with respect to the surface colour and microstructural characteristics, whilst the stability and corrosion protection of the inorganic layer were evaluated using polarization and voltammetry tests. The mechanism of the incorporation of nickel (hydr) oxide, comprising both nickel hydroxide and nickel oxide at the same time, will be discussed by taking the microstructural characteristics and the composition of the inorganic layer into account.

\section{Experimental sections}

A sheet of AZ31 Mg alloy was cut to dimensions of $30 \times 20 \times 5$ $\mathrm{mm}$. All samples were mechanically ground using SiC paper up to $\# 1200$, rinsed with distilled water, and ultrasonically cleaned in ethanol prior to the PEO process. Table 1 lists the chemical composition of the electrolytes with and without $\mathrm{Ni}\left(\mathrm{NO}_{3}\right)_{2}-$ $\cdot 6 \mathrm{H}_{2} \mathrm{O}$. A glass vessel equipped with a magnetic stirrer and a water cooling system was used as the electrolyte container. The electrolyte temperature was maintained at approximately $288 \mathrm{~K}$ to stabilize the electrochemical reactions during the PEO process. Stainless steel mesh was used as the cathode, and the sample itself was used as the anode. The PEO process was performed under an $\mathrm{AC}$ current with a constant frequency and current density of $60 \mathrm{~Hz}$ and $100 \mathrm{~mA} \mathrm{~cm}{ }^{-2}$, respectively. The surface and cross-sectional morphologies, as well as the elemental mapping of each sample, were observed using fieldemission scanning electron microscopy (FE-SEM, Hitachi S4800) coupled with an electron probe microanalyser (EPMA, JEOL JXA-8530F). The phase composition was examined using X-ray diffraction (XRD, PANalytical X'Pert PRO) with a step size of 0.05 and a scan range of 30 to 90 . Additionally, the chemical composition was analysed using X-ray photoelectron spectroscopy (XPS, ESCA PHI 5800); transmission electron microscopy (TEM, TECNAI F20) was utilized to obtain high resolution images of the nickel (hydr)oxide structures. The solar absorbance $\left(\alpha_{\mathrm{s}}\right)$ properties were measured using a UV/VIS/NIR spectrometer (Cary 5000) with scanning range of 200 to $1000 \mathrm{~nm}$ at an excitation wavelength of $325 \mathrm{~nm}$. Cyclic voltammetry measurements were performed in $3 \mathrm{wt} \% \mathrm{KOH}$ solution in the potential range of $-5.0 \mathrm{~V}$ to $5.0 \mathrm{~V}(v s . \mathrm{Ag} / \mathrm{AgCl})$ at a scan rate of $100 \mathrm{mV} \mathrm{s}^{-1}$ for 50 cycles to evaluate the electrochemical stability of the inorganic layers, and the potentiodynamic polarization tests were conducted from -0.25 to $0.4 \mathrm{~V}$ with respect to the

Table 1 Chemical composition of the electrolytes used for the PEO coatings. All measurements were performed at $288 \mathrm{~K}$, which was identical to the PEO temperature

Composition $\left(\mathrm{g} \mathrm{L}^{-1}\right)$

\begin{tabular}{lllllll} 
Sample & $\mathrm{KOH}$ & $\mathrm{KF}$ & $\mathrm{Na}_{2} \mathrm{SiO}_{3} \cdot 6 \mathrm{H}_{2} \mathrm{O}$ & $\mathrm{K}_{4} \mathrm{P}_{2} \mathrm{O}_{7}$ & $\mathrm{Ni}_{\left(\mathrm{NO}_{3}\right)_{2} \cdot 6 \mathrm{H}_{2} \mathrm{O}}$ & $\left.\mathrm{Conductivity} \mathrm{(mS} \mathrm{cm}{ }^{-1}\right)$ \\
\hline MO & 15 & 3 & 10 & 15 & - & 21.8 \\
NiMO & 15 & 3 & 10 & 15 & 10 & 22.3
\end{tabular}


open circuit potential (OCP) at a scan rate of $1 \mathrm{mV} \mathrm{s}^{-1}$ in a $3.5 \mathrm{wt} \% \mathrm{NaCl}$ solution at $\mathrm{pH} 7.0$ to evaluate the electrochemical responses related to the corrosion behaviour of the layers. Both electrochemical measurements were carried out using a potentiostat (Gamry Interface 1000) utilizing a threeelectrode cell system: the sample with an exposed area of 1 $\mathrm{cm}^{2}$ as the working electrode, a platinum plate as the counter electrode, and $\mathrm{Ag} / \mathrm{AgCl}$ as the reference electrode.

\section{Results}

\section{Plasma discharge characteristics}

The characteristics of the plasma discharges, i.e. their size, density, duration, and intensity, determined the microstructures of the resulting inorganic layer. ${ }^{21-23}$ Monitoring these characteristics during plasma electrolysis is important to understanding both the final microstructure of the inorganic layer and the incorporation mechanism of the electrolyte species. Fig. 1 shows the RMS voltage responses of the inorganic layer without (MO) and with (NiMO) the Ni-containing compounds, along with the plasma discharge characteristics at selected voltages and the physical appearance of the inorganic layer. Irrespective of the electrolyte composition, three different stages were identified based on rate of increase in the voltage with respect to the processing time. In stage I, the voltage rose at a steep rate, linear to the time increase, due to the rapid passivation of the magnesium substrate; the voltage increase stemmed from the increase of electrical resistance resulting from the growth of the passive film..$^{\mathbf{8 , 2 4 , 2 5}}$ The film continued to grow until the breakdown voltage, at which the barrier structure of film became porous, was exceeded, as represented by the gradual decrease in terms of the slope. This region of decreasing slope after the breakdown voltage was denoted as stage II. The onset of stage II was preceded by the appearance of tiny, fast-moving sparks uniformly over the sample surface accompanied by acoustic emission as a consequence of $\mathrm{O}_{2}$ gas breakdown. ${ }^{26,27}$ In regard to the breakdown mechanism, Hussein et al. postulated that it might be imitated by (i) gas breakdown at the inorganic layerelectrolyte interface, or (ii) oxide film dielectric breakdown due to high-intensity discharges. ${ }^{27}$ This model was in a good agreement with the results reported by Jovovic et al. in a study of spectroscopic characteristics during plasma discharges, ${ }^{28}$ in which massive bubbles appeared at the breakdown site and

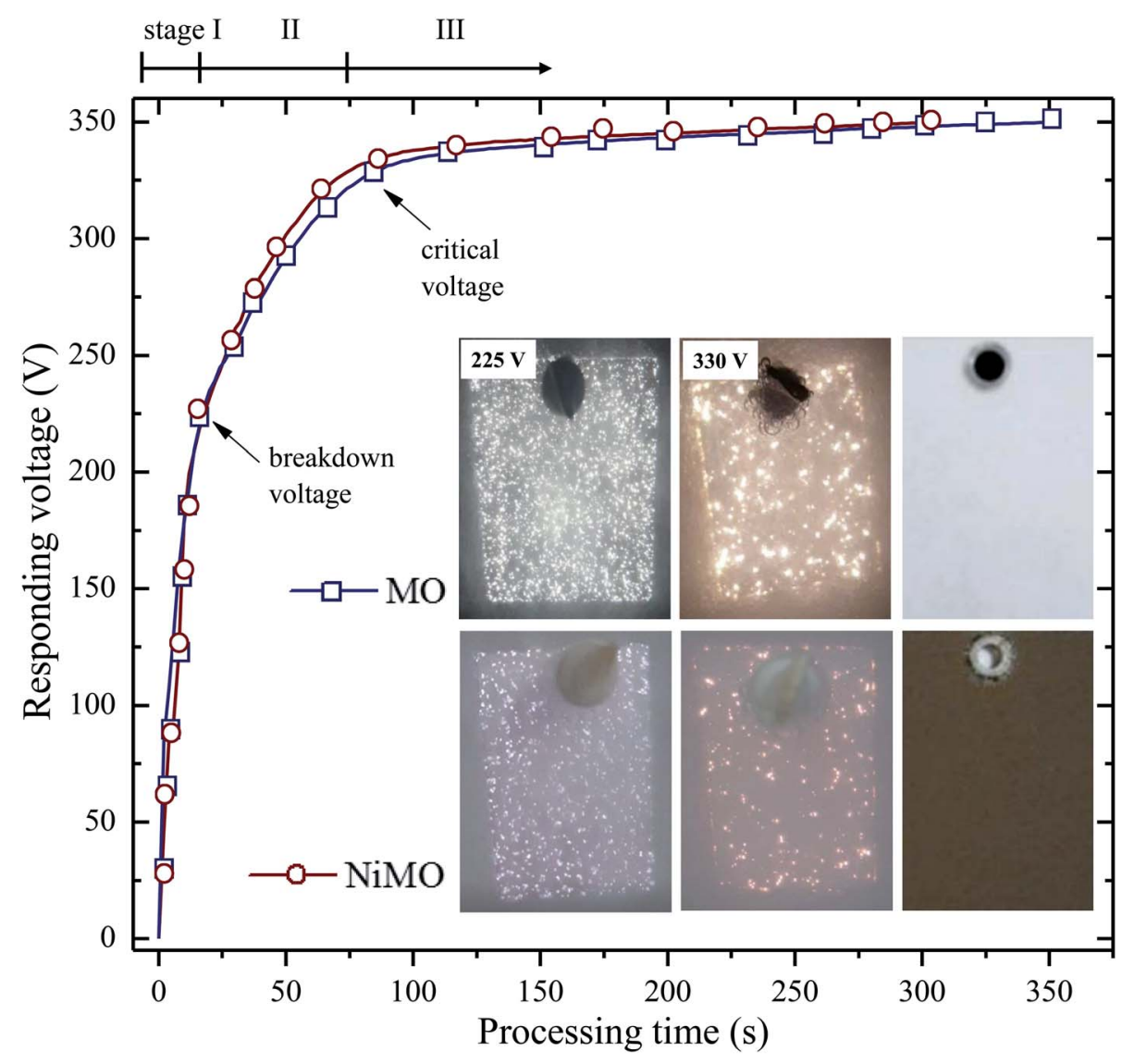

Fig. 1 Curve shows the voltage response (RMS) vs. processing time during PEO at $100 \mathrm{~mA} \mathrm{~cm}^{-2}$ without (MO) and with (NiMO) Ni-containing electrolyte. Stage I is differentiated by the steep slope of the RMS voltages with increasing time. The insets show optical images of the plasma discharges during the PEO of $\mathrm{MO}$ and $\mathrm{NiMO}$ at $225 \mathrm{~V}$ and $330 \mathrm{~V}$ from left to right, respectively. NiMO showed less intense discharges at all representative voltages as compared to those of $\mathrm{MO}$. Rightmost insets show the physical appearance of both samples; NiMO generated a darkbrown colour. 
could significantly alter the final microstructure. These reports also paralleled the findings of Cheng et al. and Troughton et al. ${ }^{29,30}$ The breakdown voltages of MO and NiMO were equal, $\sim 225 \mathrm{~V}$, as a result of the equivalent electrolyte conductivity associated with similar $\mathrm{KOH}$ concentration. ${ }^{31-33}$ Stage II was important, because it determined the characteristics of the inner layer, which served as the main contributor to corrosion protection. ${ }^{34}$ Moreover, this stage was also important to the early decoration of the inorganic layer, since the incorporation of electrolyte species would be promoted by the high energy plasma. ${ }^{35,36}$ Here, the increase of voltage was more prominent for NiMO, which might have been due to features of its inorganic layer, such as its compactness, composition, or morphology. ${ }^{37,38}$ These factors would significantly influence the plasma characteristics, such as the number of discharges and their size, duration, and energy. ${ }^{21-23}$ The voltage response tendency observed in stage II continued until the critical voltage was exceeded. Both MO and NiMO showed a similar critical voltage, indicating the beginning of stage III. During this stage, the voltage responses for both samples showed a plateauing tendency owing to their identical total resistances. This tendency would not be a function of film resistance due to the presence of dielectric fracture or electron avalanche. ${ }^{39}$

The inset in Fig. 1 shows photographs of the discharges at selected PEO voltages in stage II. Irrespective of the electrolyte composition, vigorous gas evolution was observed at $\sim 225 \mathrm{~V}$ on both samples. After the breakdown voltage was exceeded, shortlived plasma discharges emerged over the entire surface of the samples as a result of dielectric breakdown of the passive film. ${ }^{32}$ The discharge characteristics changed quickly, with notable plasma avalanches being observed at sites with the lowest resistance, ${ }^{22,30,40}$ as shown in the upper-left inset of Fig. 1. The intensity of the plasma discharges on NiMO was lower than those on MO, due to the increase in electrical resistance arising from the incorporation of Ni species..$^{\mathbf{3 6 , 4 1 - 4 3}}$ Here, the occurrence of large and high-intensity discharge cascades on the surface of MO allowed for a fast melting process, thus producing a lower voltage response as compared to NiMO.

When the voltage exceeded $\sim 330 \mathrm{~V}$, the size and intensity of the plasma discharges on both samples increased further and significant differences in the appearance of the discharges were evident. The duration of the discharge cascades was longer compared to the plasma discharges observed in the early period of stage II in both inorganic layers, which provided more time for the electrolyte species to be incorporated into the oxide layer. Inhomogeneous, bright, and vigorous discharges with a size of $\sim 1 \mathrm{~mm}$ were observed on MO, while such characteristics were absent on NiMO. This phenomenon remained obvious for the majority of processing time, until the discrepancy gradually diminished in stage III. The right-most images of the insets show the physical appearance of the inorganic layer formed via plasma electrolysis. The final colour of the inorganic layer was attributed to its chemical composition and structural morphology. The MO sample was light grey in colour, which is typical of PEO layers on $\mathrm{Mg}$ alloys, ${ }^{8}$ whilst NiMO exhibited a homogeneous dark brown colour, which might be related to the presence of nickel hydr(oxide). The homogeneous colour of NiMO was suggested to be attributed to the uniform distribution of the nickel compounds.

\section{Structure and composition of the inorganic layers}

Fig. 2(a) and (b) present the surface morphology and elemental mapping of MO and NiMO, respectively. Both inorganic layers exhibited typical PEO structures comprised of micropores and oxide nodules, which originated from the plasma discharges and the solidification of molten oxide. ${ }^{7,36,43}$ The average porosities of the MO and NiMO samples were $\sim 11.1 \%$ and $\sim 5.4 \%$, respectively. The average pore size decreased significantly from $\sim 3.5$ to $\sim 1.5 \mu \mathrm{m}$ with the incorporation of the Ni compounds. This remarkable decrease was correlated with the voltage increase observed for the NiMO sample during stage II. These results were in a good agreement with earlier studies which reported that several factors would influence the voltage response, including the morphology, composition, and thickness of the inorganic layers. ${ }^{35,38,44,45}$

The morphologies of the samples were in a good accordance with the plasma discharge characteristics observed during the PEO process, with large-sized discharges generating inorganic layers with large-sized micropores. On the other hand, soft plasma discharges promote the formation of an inorganic layer with small-sized micropores. ${ }^{\mathbf{4 6 7}}$ Additionally, elemental mapping was carried out to investigate the distribution of nickel compounds over the surface of the inorganic layer. Irrespective of the electrolyte composition, the surfaces were dominated by $\mathrm{Mg}$ and $\mathrm{O}$. This was associated with the formation of $\mathrm{MgO}$, where the substrate served as the $\mathrm{Mg}$ source, and $\mathrm{O}$ was provided by the electrolyte species. The element Ni, which was only detected in the NiMO sample, was found to be distributed across the surface profile and was more likely to be incorporated in the vicinity of the micropores. This was in a good agreement with previous findings which reported that micropores and discharge channels would be the preferential sites for incorporations due to their high surface energy and high local temperature arising from plasma discharge, respectively. ${ }^{35,36}$

Fig. 2(c) and (d) show the cross-sections and corresponding elemental mapping of MO and NiMO, respectively, to present a comprehensive insight into the distribution of the nickel compounds in the inorganic layer. A number of micropores and discharge channels were observed in MO, in accordance with the surface characteristics of the inorganic layer. On the other hand, NiMO exhibited less defect structures and fewer discharge channels as compared to MO, which was presumably due to a sealing effect arising from the incorporation of nickel compounds in the oxide layer. Through EPMA analysis of NiMO, Ni was found to be distributed throughout the entire depth of the layer, with preferential distribution in the vicinity of the micropores. Additionally, the average thicknesses of MO and NiMO were $\sim 15 \mu \mathrm{m}$ and $\sim 18 \mu \mathrm{m}$, respectively, which suggested that the plasma characteristics of NiMO were not only effective in reducing the pore size, but also beneficial in accelerating the growth of the inorganic layer. 


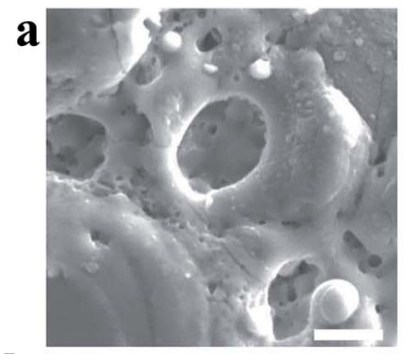

b

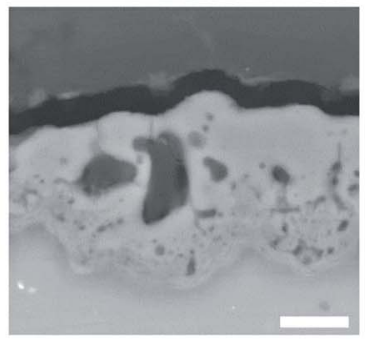

c

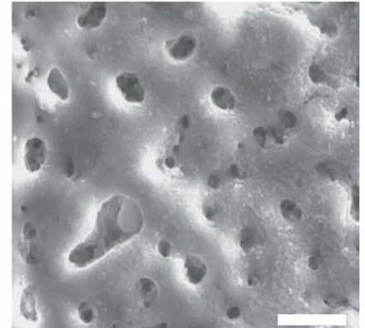

d

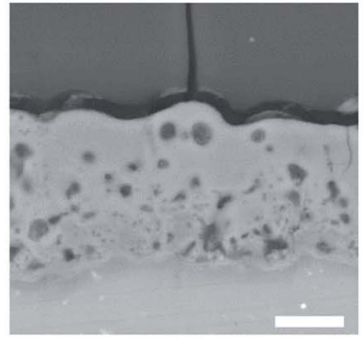

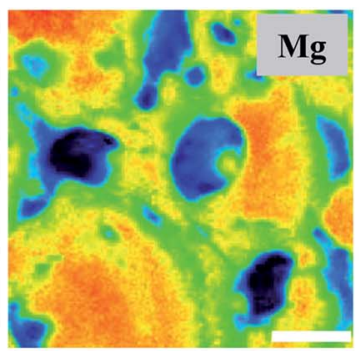
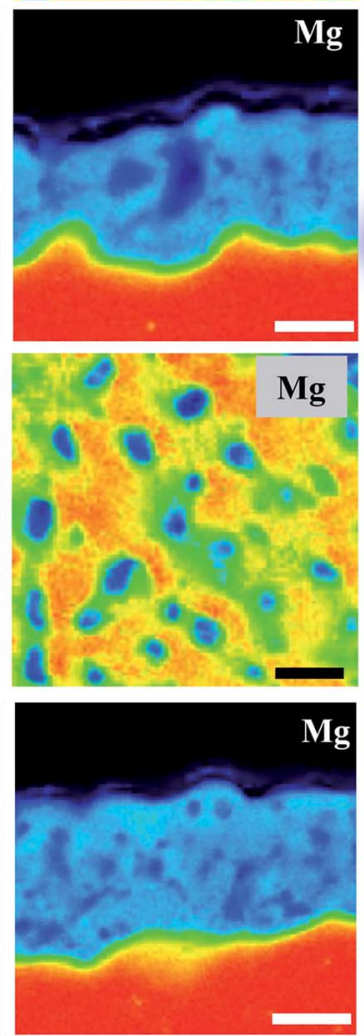

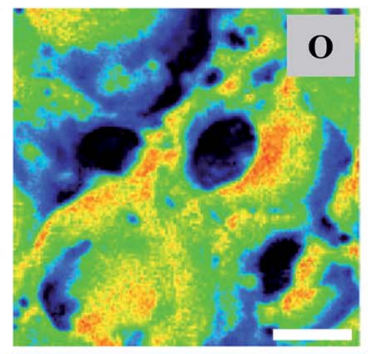

O
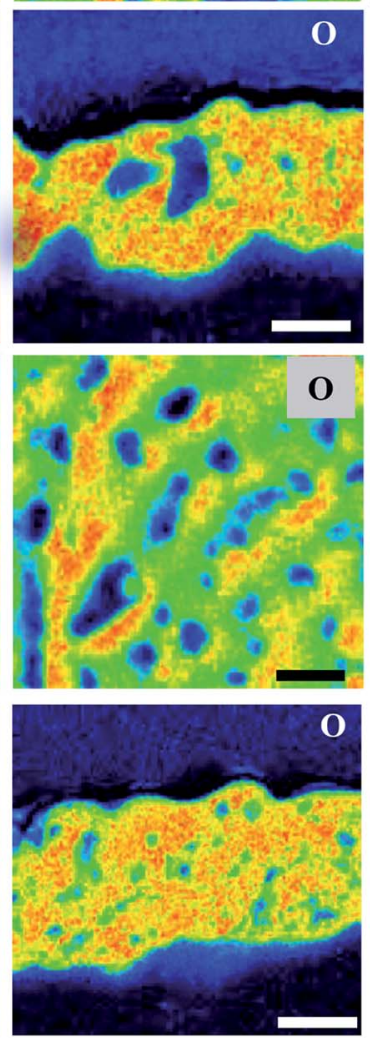
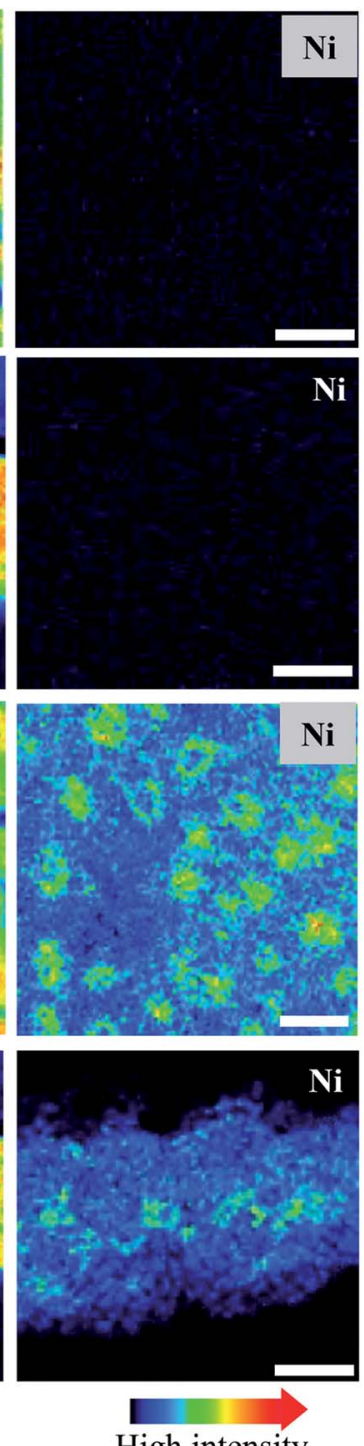

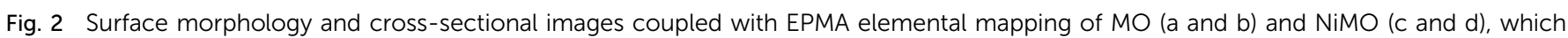

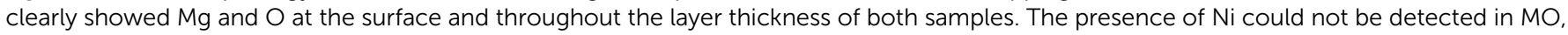

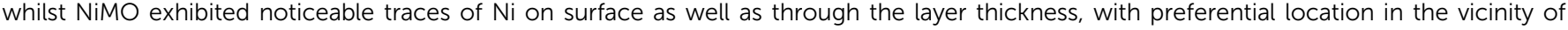
micropores and discharge channels. Scale bars $(a-d) 10 \mu \mathrm{m}$.

XRD and XPS analysis were performed to determine the chemical state of the nickel compounds in the inorganic layer, which might vary due to the complex behaviour of plasma electrolysis. Fig. 3(a) shows that $\mathrm{MgO}$ and $\mathrm{Mg}_{2} \mathrm{SiO}_{4}$ were the major components of both samples, whilst $\mathrm{Ni}(\mathrm{OH})_{2}$ and $\mathrm{NiO}$ made up a minor fraction of NiMO. The peak for $\mathrm{Ni}(\mathrm{OH})_{2}$ was detected in several position, but the most prominent was at $2 \theta$ value of 33 which was coming from diffraction of (101) plane, while NiO was at $2 \theta$ value of 43.5 from the diffraction of (200) plane.

Fig. 3(b) presents the XPS spectrum for $\mathrm{Ni} 2 \mathrm{p}_{3 / 2}$; deconvolution of the spectrum showed that the $\mathrm{Ni} 2 \mathrm{p}_{3 / 2}$ peak was divided into three peaks. The peak at a binding energy of $855.6 \mathrm{eV}$ was assigned to $\mathrm{NiO},{ }^{46-49}$ whilst the peaks at 856.2 and $857.3 \mathrm{eV}$ with a shakeup satellite at a higher binding energy of $\sim 6.5 \mathrm{eV}$ were ascribed to $\mathrm{Ni}(\mathrm{OH})_{2}{ }^{50}$ The spectrum of $\mathrm{O} 1 \mathrm{~s}$ was deconvoluted to analyse the source of the oxygen atoms on the surface. Fig. 3(c) shows that the majority of the oxygen atoms on the surface belong to $\mathrm{Ni}(\mathrm{OH})_{2}$. Judging from the area below the curve, the amount of oxygen atoms corresponding to $\mathrm{Ni}(\mathrm{OH})_{2}$ was larger than that for $\mathrm{NiO}$, which suggested that a larger fraction of the former was present. Furthermore, it was interesting to note that the majority of $\mathrm{Ni}$ was incorporated as the hydroxide form, while the main matrix, $\mathrm{MgO}$, was in the oxide form. This might be related to the higher transformation temperature of $\mathrm{Ni}(\mathrm{OH})_{2}(\sim 503 \mathrm{~K})$ as compared to that of $\mathrm{Mg}(\mathrm{OH})_{2}(\sim 410 \mathrm{~K}) .^{51,52}$

Although its concentration was lower than that of $\mathrm{Ni}(\mathrm{OH})_{2}$, the presence of $\mathrm{NiO}$ was confirmed by the dark colour of NiMO, which agreed well with previous study reporting that characteristic colour of NiO is dark brown..$^{53}$ While the formation of a metastable phase such as $\mathrm{Ni}_{2} \mathrm{O}_{3}$ could occur at $573-773 \mathrm{~K},{ }^{54}$ 
$\mathbf{a}$
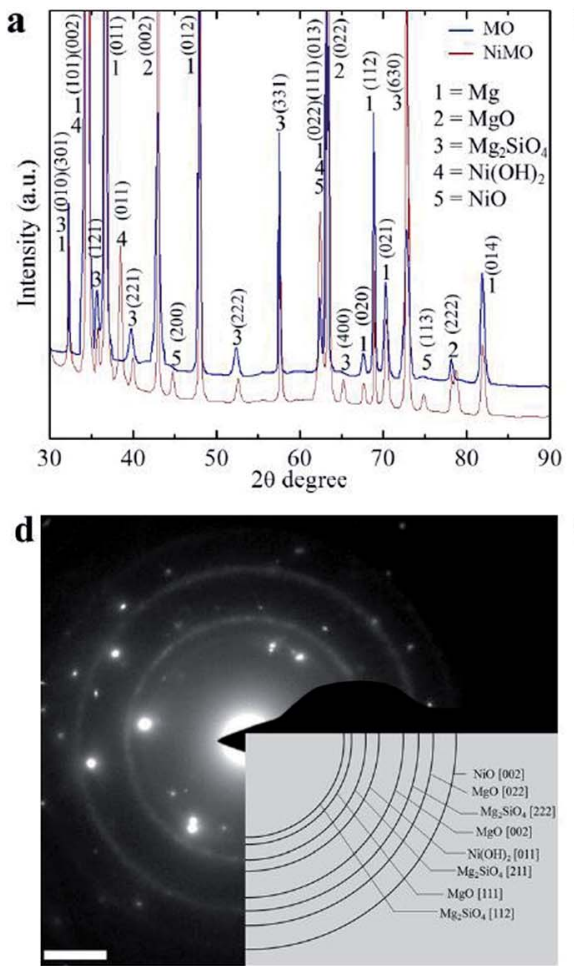

b
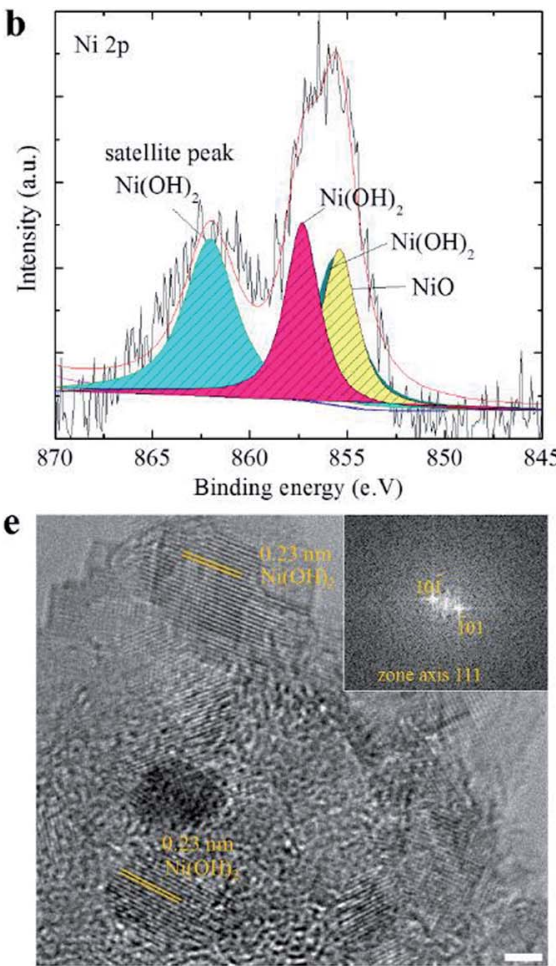

c

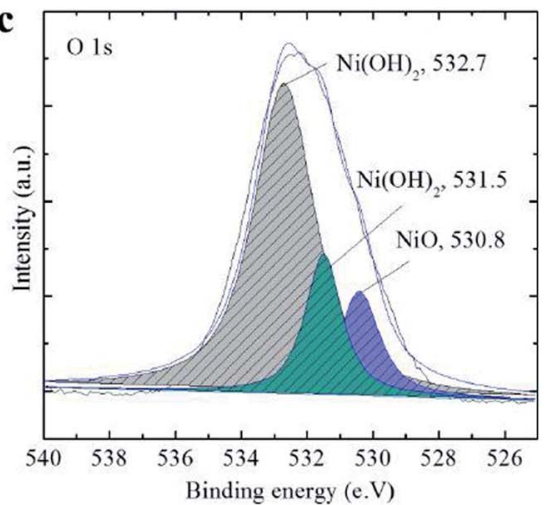

f

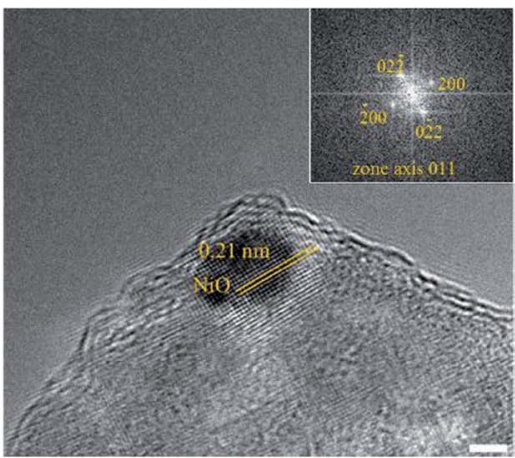

Fig. 3 (a) Representative XRD peaks of both $\mathrm{MO}$ and $\mathrm{NiMO}$ samples. The scan range area from 30 to $90^{\circ}$ with $\mathrm{Cu} \mathrm{K} \alpha$ radiation source. $\mathrm{MgO}$ and $\mathrm{Mg}_{2} \mathrm{SiO}_{4}$ as the major coating components were identified from both $\mathrm{MO}$ and $\mathrm{NiMO}$, while $\mathrm{NiO}$ and $\mathrm{Ni}(\mathrm{OH})_{2}$ were detected solely in $\mathrm{NiMO}$. The peak notation and corresponding plane are arranged in sequences. (b) XPS spectrum analysis of $\mathrm{Ni} 2 \mathrm{p}_{3 / 2}$ for NiMO, which indicated the presence of $\mathrm{Ni}(\mathrm{OH})_{2}$ as the major $\mathrm{Ni}$ species, whilst the minority species was $\mathrm{NiO}$. (c) XPS spectrum deconvolution of $\mathrm{O} 1 \mathrm{~s}$ for $\mathrm{NiMO}$, which revealed the

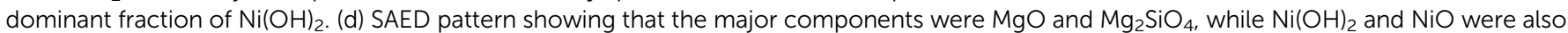
clearly detected as minor components. (e and f) HRTEM images showing the lattice spacing and corresponding $\mathrm{FFT}$ patterns of $\mathrm{Ni}(\mathrm{OH})_{2}$ and $\mathrm{NiO}$, respectively. Scale bar of (d) $100 \mathrm{~nm}$, (e and f) $21 / \mathrm{nm}$.

this phase was not detected in the NiMO, presumably because the quenching rate during the electrolysis was too high to allow the transformation, or because high plasma temperatures above $4500 \mathrm{~K}$ (ref. 7 and 8) with non-equilibrium behaviour favoured the conversion of the metastable phase into NiO. ${ }^{55}$ The microstructure of NiMO was studied in detail using transmission electron microscopy (TEM) and the selected area electron diffraction (SAED) pattern in order to confirm the existence of $\mathrm{Ni}(\mathrm{OH})_{2}$ as well as NiO. The SAED pattern shown in Fig. 3(d) in accord with the XRD findings, revealing the existence of $\mathrm{MgO}$, $\mathrm{Mg}_{2} \mathrm{SiO}_{4}, \mathrm{NiO}$, and $\mathrm{Ni}(\mathrm{OH})_{2}$ in NiMO. Those compounds likely originated from species existing in the electrolyte, and were incorporated into the inorganic layer with the aid of the electrophoretic force as well as the high plasma energy. ${ }^{31}$ Fig. 3(e and f) show the HR-TEM image of NiMO. The lattice parameter analysis seen in Fig. 3(e) indicated that several areas of the hybrid layer had a lattice distance equal to $0.23 \mathrm{~nm}$, which corresponds to the 011 plane of $\mathrm{Ni}(\mathrm{OH})_{2}$, whilst the area shown in Fig. 3(f) had a lattice distance of $0.21 \mathrm{~nm}$, corresponding to the 002 plane of NiO. ${ }^{5-57}$

\section{Solar absorbance properties of the inorganic layers}

The optical properties of the hybrid layers were characterized using light reflectivity, solar absorptivity, and infra-red emissivity. Fig. 4(a) reveals a significant reduction in the average reflectivity value, from $\sim 50 \%$ to $\sim 15 \%$, with the incorporation of $\mathrm{Ni}(\mathrm{OH})_{2}$. The solar absorbance $\left(\alpha_{\mathrm{s}}\right)$ of the inorganic layers was evaluated by measuring the increase in the of UV-Vis absorbance spectra shown in Fig. 4(b) at wavelengths from 200 to $1000 \mathrm{~nm}$, which is the range of visible light that human eyes can perceive. MO exhibited a relatively low $\alpha_{\mathrm{s}}$ of $\sim 0.4$ at $200 \mathrm{~nm}$ while the $\alpha_{\text {s }}$ peak of NiMO was $\sim 0.9$ at $214 \mathrm{~nm}$; this wavelength specifically corresponds to $\mathrm{Ni}(\mathrm{OH})_{2}$. In addition, peak at 384 would also be addressed to the hydroxide form of Ni. ${ }^{58}$ However, the peak associated with $\mathrm{NiO}$ at $295 \mathrm{~nm}$ was hardly detected, presumably due to the low fraction of NiO in NiMO.

Since the absorbance values of the two samples were significantly different, and all the only difference in their preparation was the use of the additive, the discrepancy in their absorbance characteristics was attributed solely to the nickel (hydr)oxide. The increase in absorbance was believed to result from changes in the surface colour, composition, and thickness of NiMO due to the incorporated $\mathrm{Ni}(\mathrm{OH})_{2}$ and $\mathrm{NiO}$, which absorbed a large amount of solar radiation in the UV-Vis region, thus improving the absorbance of the hybrid layer.

Ma et al. ${ }^{59}$ and LeBlanc et al. ${ }^{60}$ reported that high $\alpha_{\mathrm{s}}$ values were mainly related to the richness of transition metal oxide in the inorganic layer. Here, $\mathrm{Ni}(\mathrm{OH})_{2}$ was found to play a greater 

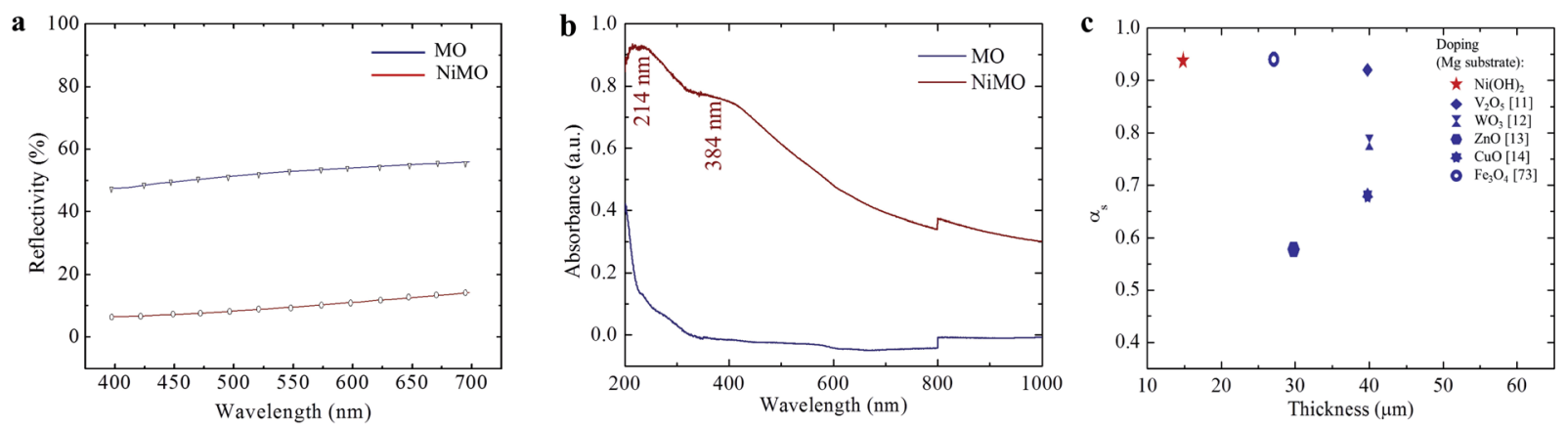

Fig. 4 (a) Reflectivity-wavelength curve of both coatings at the scanning range of 200 to $1000 \mathrm{~nm}$ with an excitation wavelength of $325 \mathrm{~nm}$ showed average reflectivities of $\sim 50 \%$ and $\sim 15 \%$ for $\mathrm{MO}$ and NiMO, respectively. (b) Absorbance $\left(\alpha_{\mathrm{s}}\right)$ value in the UV-Vis-NIR range for both samples, showing the significant absorptivity of the NiMO samples at $214 \mathrm{~nm}$ and less significant peak at $384 \mathrm{~nm}$ which were ascribed to Ni(OH) 2 . (c) $\alpha_{s} /$ thickness ratio of the PEO coating on the magnesium alloy with the variation of incorporated transition elements indicated by the symbols. The present results for NiMO showed a high solar absorbance $\left(\alpha_{s}\right)$ value with a lower thickness than the other PEO coatings.

role in light absorption based on the intensity of the peak at $214 \mathrm{~nm}$ due to its higher content in the sample. In turn, the higher $\mathrm{Ni}(\mathrm{OH})_{2}$ content arose from the high quenching rate during the PEO process, which impeded the transformation of $\mathrm{Ni}(\mathrm{OH})_{2}$ to $\mathrm{NiO}$ while promoting the formation of $\mathrm{Ni}(\mathrm{OH})_{2}$. The high electrical resistance of the inorganic layer due to the incorporation of $\mathrm{Ni}(\mathrm{OH})_{2}$ might be responsible for stabilizing soft plasma, which prevented violent discharges and fostered the growth of the inorganic layer. The increase in thickness would enhance the light absorption ability of the hybrid layer and improve its photochemical performance. ${ }^{59}$ Fig. $4(\mathrm{c})$ presents a comparison of the $\alpha_{\mathrm{s}}$ values and the thickness ratios of the inorganic layers produced with $\mathrm{MgO}$ by employing various dopants. The hybrid layer reported in this work showed excellent absorbance despite having a relatively thin inorganic layer compared to the other materials.

As mentioned above, high absorbance and low infrared emittance would be desirable properties for high efficiency materials. The thermal emissivity was calculated according to the method described in ref. 2, using a wavelength range of 250$2500 \mathrm{~nm}$, which would cover most radiation at a temperature of $373 \mathrm{~K}$, as shown below:

$$
\begin{gathered}
\varepsilon=\frac{\int_{2.5}^{25} A(\lambda) I_{\mathrm{b}}(\lambda, \mathrm{T}) \mathrm{d} \lambda}{\int_{2.5}^{25}(\lambda, \mathrm{T}) \mathrm{d} \lambda} \\
I_{\mathrm{b}}(\lambda, T)=\frac{2 \pi h c^{2}}{\lambda^{5}\left(\mathrm{e}^{h c / k \lambda T}-1\right)}
\end{gathered}
$$

where $\lambda$ is the wavelength in micrometres, $A(\lambda)$ is the absorbance value at the wavelength $\lambda$, and $I_{\mathrm{b}}(\lambda, T)$ is the blackbody spectral radiation at the temperature $T$. The solar absorbance

Table 2 Solar absorbance measurement and total emissivity calculated in the wavelength range $200-2500 \mathrm{~nm}$

\begin{tabular}{lll}
\hline Sample & Solar absorbance $\left(\alpha_{\mathrm{s}}\right)$ & Solar emissivity $(\varepsilon)$ \\
\hline MO & 0.43 & 2.10 \\
NiMO & 0.92 & 1.34
\end{tabular}

and solar emittance values are listed in Table 2. NiMO exhibited high absorbance and lower emittance values, which suggested that its energy efficiency $\left(\alpha_{\mathrm{s}} / \varepsilon\right)$ was much superior to that of MO. These optical properties were related to the composition as well as the microstructure of the inorganic layers. Thus, to confirm the microstructure of the inorganic layers electrochemical tests and to investigate their corrosion resistance, electrochemical tests were conducted on both samples.

\section{Electrochemical performance analysis of the hybrid layer}

The electrochemical stability of MO and NiMO were evaluated by performing cyclic voltammetry (CV) in a $3 \mathrm{wt} \% \mathrm{KOH}$ solution with a scan rate of $100 \mathrm{mV} \mathrm{s}^{-1}$ over the potential range $-5.0 \mathrm{~V}$ to $5.0 \mathrm{~V}$ vs. an $\mathrm{Ag} / \mathrm{AgCl}$ electrode as a reference. Fig. 5(a) shows the current-potential characteristics of the inorganic layers over the course of $24 \mathrm{~h}$. Three distinct regions of current were identified due to double layer formation, oxygen evolution, and hydrogen evolution. The current in these regions was altered in the presence of Ni owing to the disparity in the accessible surface area of the inorganic layers. The higher current in MO implied that its inorganic layer was more porous, meaning that more active sites were exposed to the electrolytic ions. ${ }^{61}$

The cations and anions from the $\mathrm{KOH}$ electrolyte were adsorbed on the inorganic layer during the anodic process, and then desorbed during the reverse scan. Both samples showed similarly shaped curves with no reduction-oxidation (redox) peaks in the double layer region, indicating that the inorganic layers were electrochemically stable. To be more precise, the narrow area bounded by the curve in the double layer region of NiMO was smaller than that of MO, indicating that NiMO was more resistant to redox reactions. In addition, NiMO showed a large electrochemical window of up to $3.0 \mathrm{~V}$ without any noticeable redox peaks, indicating that this sample could be employed for applications with operation voltages of -3.0 to $3.0 \mathrm{~V}^{62,63}$ The CV profiles of both samples shown in Fig. 5(b) revealed that the anodic and cathodic currents increased quickly with repeated cycling. This indicated that with increasing cycle number, more active sites were exposed to the electrolytic ions. However, the stability of the NiMO remained 

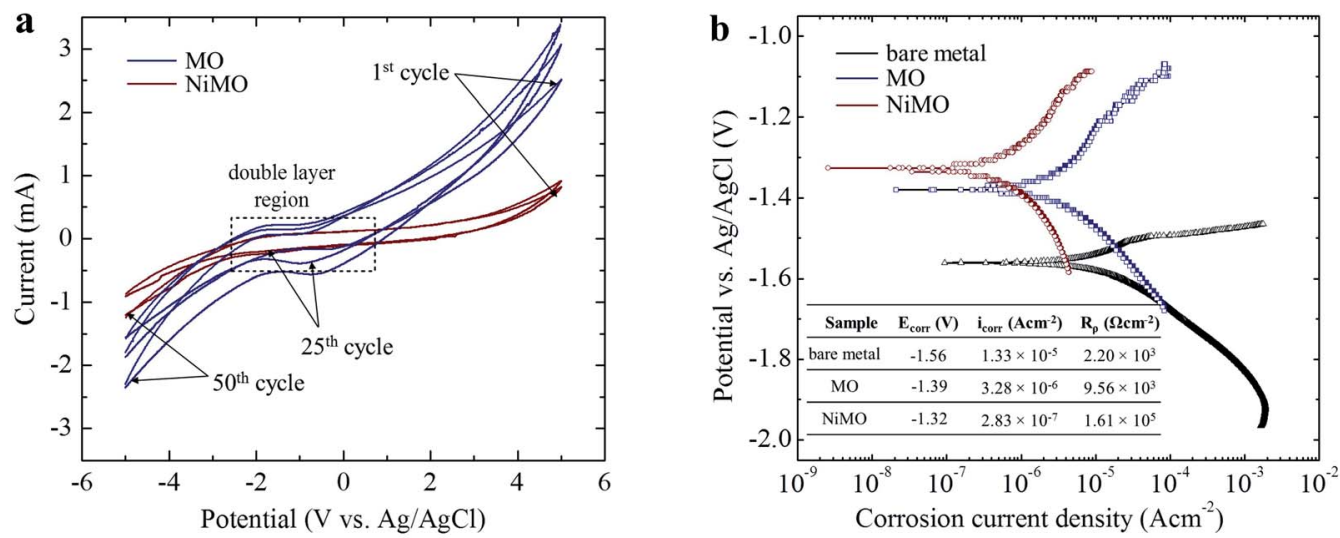

Fig. 5 (a) Cyclic voltammograms of $\mathrm{MO}$ and NiMO performed in a three-electrode system ( $\mathrm{Pt}, \mathrm{Ag} / \mathrm{AgCl}$, analysed sample) at a scan rate of $100 \mathrm{mV} \mathrm{s}^{-1}$ in $3 \mathrm{wt} \% \mathrm{KOH}$ solution. No reduction-oxidation peaks were detected in either sample. NiMO had the highest electrochemical stability at cycle number 50. (b) Potentiodynamic polarization curves of bare $\mathrm{Mg}$ alloys, $\mathrm{MO}$, and $\mathrm{NiMO}$ samples in a $3.5 \mathrm{wt} \% \mathrm{NaCl}$ solution vs. Ag/AgCl electrode. NiMO shows significantly improved corrosion protection, which arose from the presence of incorporated nickel (hydr)oxide.

unchanged, as evidenced by the absence of any redox peaks in the double layer region.

On the other hand, previous studies suggested that $\mathrm{Ni}(\mathrm{OH})_{2}$ might undergo an oxidation reaction under electrochemical testing, as given by the Glemser and Einerhand reaction below.

$$
\mathrm{Ni}(\mathrm{OH})_{2}+\mathrm{OH}^{-} \leftrightarrow \mathrm{NiOOH}+\mathrm{H}_{2} \mathrm{O}+\mathrm{e}^{-}
$$

However, this phenomena was unlikely to occur in the present work, probably due to the strong bonding between the $\mathrm{MgO}$ matrix and $\mathrm{Ni}(\mathrm{OH})_{2}$ arising from similar atomic radii of $0.083 \mathrm{~nm}$ and $0.086 \mathrm{~nm}$ from $\mathrm{Ni}^{2+}$ and $\mathrm{Mg}^{2+}$ ions, respectively. ${ }^{64}$ To support this result, the electrochemical responses of the inorganic layers related to their corrosion behaviour were assessed by potentiodynamic polarization in a $3.5 \mathrm{wt} \% \mathrm{NaCl}$ solution. By means of Tafel least-squares fitting method, the anodic and cathodic Tafel slopes $\left(\beta_{\mathrm{a}}\right.$ and $\beta_{\mathrm{c}}$, respectively), corrosion potential $\left(E_{\text {corr }}\right)$, and corrosion current density $\left(i_{\text {corr }}\right)$ values were derived from the polarization curves, and are summarized in Table 3 . The polarization resistance $\left(R_{\rho}\right)$ values reflecting the corrosion resistances of the samples were determined in accordance with the Stern-Geary equation, ${ }^{55}$ shown below,

$$
R_{\rho}=\frac{\beta_{\mathrm{a}} \beta_{\mathrm{c}}}{2.303 i_{\text {corr }}\left(\beta_{\mathrm{a}}+\beta_{\mathrm{c}}\right)}
$$

Fig. 5(a) shows the polarization curves of the bare metal, MO, and NiMO, with the $E_{\text {corr }}$ value following the order bare metal <
MO $<$ NiMO, and the $i_{\text {corr }}$ values following the reverse order, NiMO $<$ MO $<$ bare metal. High $E_{\text {corr }}$ and low $i_{\text {corr }}$ values represent superior corrosion properties. $^{32}$ The corrosion protection of MO was improved considerably as compared to the bare metal which indicated by the shift of $E_{\text {corr }}$ value to more positive potential, $i_{\text {corr }}$ value to smaller density, and appreciable increase of $R_{\rho}$ value. These phenomena would be coming from the protection given by inorganic layer, which composed mainly of $\mathrm{MgO}$ and $\mathrm{Mg}_{2} \mathrm{SiO}_{4}$, which generally known having higher chemical stability as compared to that of bare $\mathrm{Mg}$ alloys.

In addition, the $R_{\rho}$ of NiMO was approximately two orders of magnitude higher than that of MO, indicating $\sim 100$ times greater corrosion protection. ${ }^{65}$ This result was consistent with the $\mathrm{CV}$ profile, in which the incorporation of $\mathrm{Ni}(\mathrm{OH})_{2}$ sealed the micro-pores and discharge channels found in the inorganic layer, thus generating a denser structure with lower porosity and reducing the accessible surface area for the corrosive agents $\left(\mathrm{Cl}^{-}\right.$ions) to penetrate the inorganic layer. This finding was also in agreement with a previous study by Luo et al. ${ }^{66}$ in which the high thickness and excellent compactness of the inorganic layer were reported to lead to good barrier properties and a stable microstructure during long-term immersion in a corrosive environment.

\section{Discussion}

\section{Mechanism for the incorporation of $\mathrm{Ni}(\mathrm{OH})_{2}$ and $\mathrm{NiO}$}

The incorporation of electrolyte species into the inorganic layer typically occurred through high-temperature reactions that took

Table 3 Potentiodynamic polarization results of the bare metal, $\mathrm{MO}$, and $\mathrm{NiMO}$ in a $3.5 \mathrm{wt} \% \mathrm{NaCl}$ solution. $E_{\mathrm{corr}}, I_{\mathrm{corr}}, \beta_{\mathrm{a}}$, and $\beta_{\mathrm{c}}$ were derived by Tafel extrapolation. $R_{\rho}$ was calculated based on the Stern-Geary equation

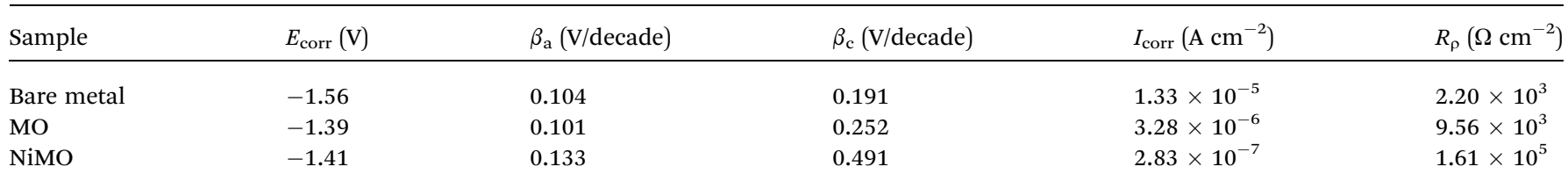


place in the discharge channels or adjacent areas. The plasma electron temperature of the ignited discharges on the surface of the substrate was $\sim 4500-11000 \mathrm{~K}$ (ref. 34) whilst the pressure was $\sim 0.2-100 \mathrm{GPa}^{7}$ At the beginning of the PEO, the temperature reached $\sim 4500 \mathrm{~K}$, and increased to $4800-5200 \mathrm{~K}$ when strong plasma discharges appeared. ${ }^{7}$ This value was much greater than the actual temperature of the molten magnesium oxide owing to the localization of the high-temperature discharges. A study by Lee et al. on PEO of $\mathrm{Mg}$ alloys by utilizing two kinds of stable particles with different melting points, suggested that the plasma temperature involved during PEO was in the range of $2116-2643 \mathrm{~K}^{34}$ Due to this high temperature, a strong perturbation which might arise from the molten oxide would facilitate the incorporation of electrolyte species near the metal-electrolyte interface. ${ }^{34}$ During plasma electrolysis, cationic species, in this case $\mathrm{Ni}^{2+}$, would likely be repelled by the positive anode. Nevertheless, $\mathrm{Ni}^{2+}$ could be incorporated into the inorganic layer for two possible reasons: (i) the principle of electric neutrality of plasma and (ii) the adsorption of phosphate as one of the electrolyte species. ${ }^{\mathbf{6 6 , 6 7}}$ More importantly, in an alkaline electrolyte, $\mathrm{Ni}^{2+}$ tends to form $\mathrm{Ni}(\mathrm{OH})_{2}$, which would be followed by the formation of anion complexes as shown in eqn (7), would move readily towards the positive anode. ${ }^{68}$ In addition, the electrolyte was stirred throughout the PEO process, assisting the incorporation of particles. ${ }^{31}$ The vigorous plasma discharges further facilitated the incorporation of $\mathrm{Ni}(\mathrm{OH})_{2.4}{ }^{0.4-}$ into the inorganic layer. $\mathrm{Ni}^{2+}$ was produced by the dissociation of nickel nitrate in water, as shown in eqn (5), and subsequently reacted with $\mathrm{OH}^{-}$, which originated primarily from the basic electrolyte and secondarily from the reduction of $\mathrm{O}_{2}, \mathrm{NO}_{3}{ }^{-}$, and $\mathrm{H}_{2} \mathrm{O}$ to produce $\mathrm{Ni}(\mathrm{OH})_{2}$, as shown in eqn (6). The instantaneous high temperature and pressure around the discharge channels during the PEO process led to partial the oxidation of $\mathrm{Ni}(\mathrm{OH})_{2}$ to form $\mathrm{NiO}$, as described in eqn (8).

$$
\begin{gathered}
\mathrm{Ni}\left(\mathrm{NO}_{3}\right)_{2} \cdot 6 \mathrm{H}_{2} \mathrm{O} \rightarrow \mathrm{Ni}^{2+}+2 \mathrm{NO}_{3}{ }^{-}+6 \mathrm{H}_{2} \mathrm{O} \\
\mathrm{Ni}^{2+}+2 \mathrm{OH}^{-} \rightarrow \mathrm{Ni}(\mathrm{OH})_{2} \\
\mathrm{Ni}(\mathrm{OH})_{2}+0.4 \mathrm{OH}^{-} \rightarrow \mathrm{Ni}(\mathrm{OH})_{2.4}{ }^{0.4-} \\
2 \mathrm{Ni}(\mathrm{OH})_{2}+2 \mathrm{OH}^{-} \stackrel{\sim 503 \mathrm{~K}}{\longrightarrow} 2 \mathrm{NiO}+2 \mathrm{H}_{2} \mathrm{O}+2 \mathrm{e}^{-}
\end{gathered}
$$

A mechanism for the incorporation of $\mathrm{Ni}(\mathrm{OH})_{2}$ and $\mathrm{NiO}$ based on the microstructure of the hybrid layer was proposed and is represented in Fig. 6. In this mechanism, $\mathrm{Ni}(\mathrm{OH})_{2}$ was incorporated on the surface of the passive film during the initial stage of PEO. The oxidation reaction accelerated the growth rate of the inorganic layer during the PEO process to form a thick inorganic layer. ${ }^{67}$ When the breakdown voltage was exceeded, the barrier structure of the film became porous, and concurrently, the incorporation of $\mathrm{Ni}$ was enhanced by the plasma discharges ignited on the anode surface via the strong fluctuations in molten magnesium oxide that promoted the incorporation of $\mathrm{Ni}^{69}$ As the voltage raised, the intensity and size of the plasma discharges would be reduced which might be due to the enhanced incorporation of $\mathrm{Ni}$ ions with stable oxidation state such as $\mathrm{Ni}(\mathrm{OH})_{2}$ and $\mathrm{NiO}$, which improved the coating compactness, thus allowing the layer to withstand a strong electric field, reducing the destructive effect and generating smaller size of plasma discharges. Accordingly, the hybrid layer would have a smaller pore size and lower porosity, as depicted in Fig. 2(b).

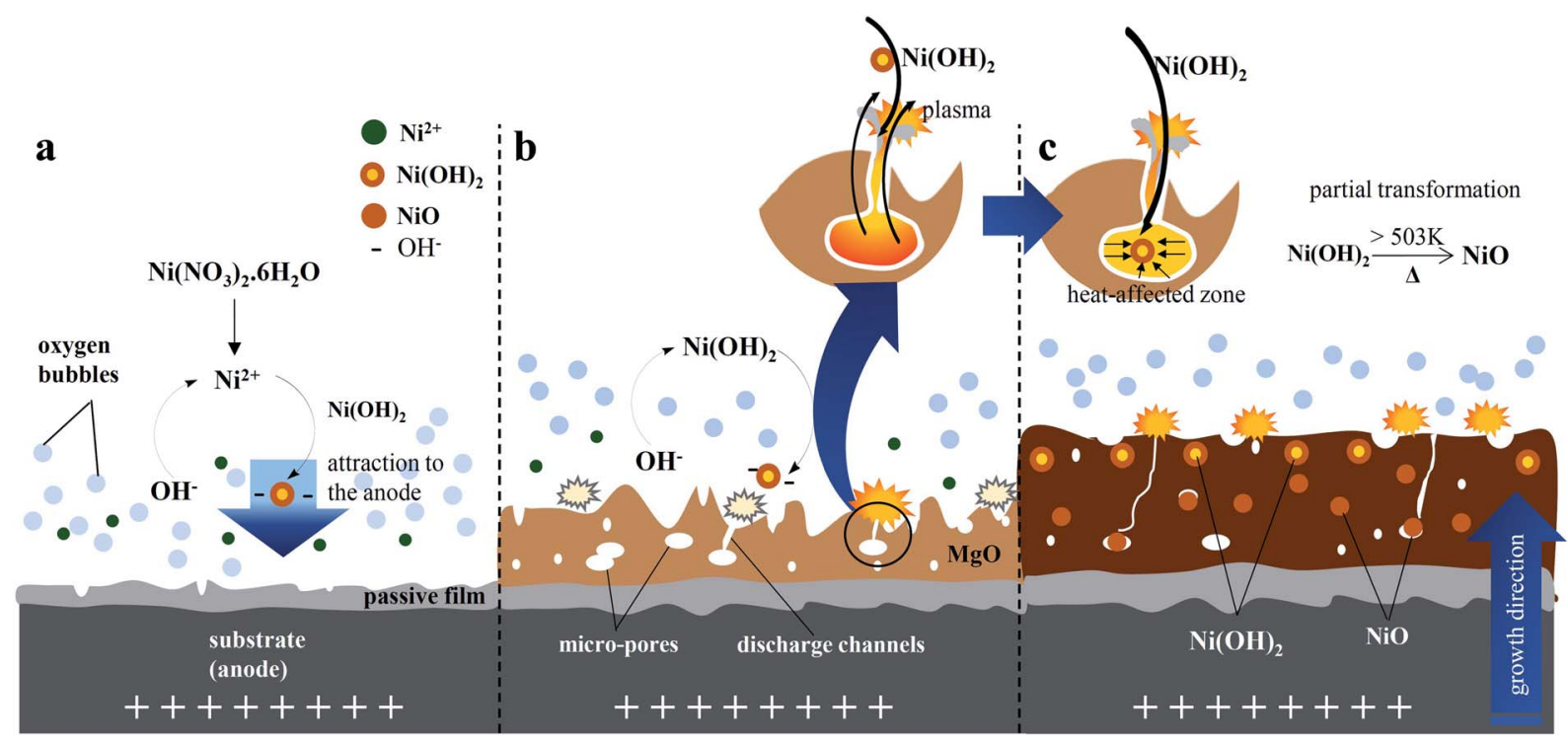

Fig. 6 Schematic illustration of the suggested incorporation mechanism for $\mathrm{Ni}(\mathrm{OH})_{2}$ based on the NiMO microstructure, comprising three steps: (a) $\mathrm{Ni}(\mathrm{OH})_{2}$ formed during the initial stage of coating process would be deposited on the top of the passive film. (b) The incorporation of Ni(OH) occurs after the breakdown voltage is exceeded, and the ignited plasma discharges generate micro-defects. (c) In the presence of the incorporated $\mathrm{Ni}(\mathrm{OH})_{2}$, the plasma becomes softer and more homogeneous. The high quenching rate suppresses the transformation of $\mathrm{Ni}(\mathrm{OH})_{2}$ to $\mathrm{NiO}$. 


\section{Solar absorbance properties of the inorganic layers}

The incorporation of nickel (hydr)oxide led to high solar absorbance in the wavelength range of visible-light because the transition element $\mathrm{Ni}$ acted as a colouring agent that could absorb most of the light radiation. Transition elements such as $\mathrm{Ni}, \mathrm{Fe}, \mathrm{Cu}$, and $\mathrm{Mn}$ have d-electron orbitals, and both the outermost and the second-outermost electron shells of these elements are unsaturated. When the light radiation falls on an inorganic layer containing those kinds of elements or ions, electron transfer takes place between the outermost and the second-outermost electronic shells. Consequently, absorption takes place at the corresponding wavelength, and the inorganic layer exhibits the complementary colour of the corresponding wavelength. ${ }^{70,71}$

The solar absorbance has also been reported to depend on the structure and composition of the inorganic layer. ${ }^{72}$ A very thick inorganic layer reduces reflectivity and enhances the solar absorbance. The incorporation of nickel (hydr)oxide produced inorganic layers with a higher thickness due to the increase of layer growth and the decrease of micro-defect density induced by fine plasma discharges. This might enhance the efficiency of the inorganic layer as a light trapping material. ${ }^{73-75}$ In addition, the electrical resistance of an inorganic layer also affects its reflectivity. Chang et al. ${ }^{76}$ reported that light reflection, $R$, was inversely related to the electrical resistance, $\rho$, as described in eqn (9).

$$
R=1-A \rho^{1 / 2}
$$

To compare the performance of NiMO with previous reports of magnesium alloy substrates doped with other transition elements during the PEO process, ${ }^{67,71,77,78}$ the $\alpha_{\mathrm{s}} /$ thickness-ratios of the inorganic layers are presented in Fig. 6. The layer containing Ni showed the highest $\alpha_{\mathrm{s}} /$ thickness ratio. This indicates that despite its lower thickness, the inorganic layer could absorb a greater amount of light radiation compared to other inorganic layers with greater thicknesses. It is worth noting that this layer would be desirable for solar absorber applications which require a thin layer, such as thin film solar cells and wearable devices. The high $\alpha_{\mathrm{s}}$ /thickness-ratio could be attributed to two main factors. First, NiMO exhibited a denser structure than MO. According to Yao et al. ${ }^{79}$ the solar absorbance is mainly related to the structure and composition of the inorganic layer, and the absorbance increases with the formation of a more compact structure. Second, the incorporation of $\mathrm{NiO}$ and $\mathrm{Ni}(\mathrm{OH})_{2}$ throughout the entire depth of the inorganic layer could be responsible for the increase in light absorption.

\section{Conclusions}

A hybrid inorganic layer with a thickness of $\sim 15 \mu \mathrm{m}$ in which a $\mathrm{MgO}$ matrix was decorated with nickel (hydr)oxide was fabricated via green plasma electrolysis in an alkaline electrolyte. After the onset of breakdown phenomena, the incorporation of nickel (hydr)oxide was achieved uniformly throughout the hybrid inorganic layer by means of soft plasma discharges. The soft discharges were related to (i) the presence of colloidal
$\mathrm{Ni}(\mathrm{OH})_{2}$, which impedes the high electrical field in the present electrolyte and (ii) the incorporation of nickel (hydr)oxide, which lowers the electrical conductivity of the inorganic layer. Electrochemical analyses using cyclic voltammetry and potentiodynamic polarization measurements suggested that the hybrid inorganic layer exhibited good electrochemical stability even in a corrosive environment due its low porosity of $\sim 5.4 \%$, which resulted from the incorporation of nickel (hydr)oxide. Interestingly, the hybrid inorganic layer shows a high solar absorptivity of $\sim 0.92$ and a low infrared emissivity of $\sim 0.13$. Accordingly, a high ratio of solar absorptivity to thickness was achieved in the present hybrid inorganic layer using pollutionfree processing; this method will have implications in the development of desirable functional materials for aerospace and sustainable energy applications with excellent surfacecontrolled characteristics.

\section{Conflicts of interest}

There are no conflicts to declare.

\section{Acknowledgements}

We acknowledge the Research Project (NRF2018H1D2A2010032) and the First Research Grant (NRF2017R1C1B5077139) of the National Research Foundation funded by the Ministry of Science and ICT, Republic of Korea. This is supported partly by Nano-Material Technology Development Program (2009-0082580).

\section{References}

1 P. A. Buser and M. Imbert, Vision, MIT Press, 1992, ISBN 9780-262-02336-8.

2 A. B. Kaul, J. B. Coles, M. Eastwood, R. O. Green and P. R. Bandaru, Ultra-High Optical Absorption Efficiency From The Ultraviolet To The Infrared Using Multi-Walled Carbon Nanotube Ensembles, Small, 2013, 9, 1058-1065.

3 M. A. Estrella-Gutiérrez, F. I. Lizama-Tzec, O. Arés-Muzio and G. Oskam, Influence of A Metallic Nickel Interlayer on the Performance of Solar Absorber Coatings Based on Black Nickel Electrodeposited onto Copper, Electrochim. Acta, 2016, 213, 460-468.

4 F. He, H. Su, H. Ju, L. Tan and Q. Zhou, A New Blackening Process for NiWP Alloy Deposits, Surf. Coat. Technol., 2012, 213, 133-138.

5 F. Xing, B. Zhao and W. Shi, Study on Tunable Fabrication of the Ultra-Black Ni-P Film and Its Blacking Mechanism, Electrochim. Acta, 2013, 100, 157-163.

6 A. Nominé, J. Martin, C. Noël, G. Henrion, T. Belmonte, I. V. Bardin and P. Lukeš, Surface Charge at the Oxide/ Electrolyte Interface: Toward Optimization of Electrolyte Composition for Treatment of Aluminum and Magnesium by Plasma Electrolytic Oxidation, Langmuir, 2016, 32, 14051409. 
7 A. L. Yerokhin, X. Nie, A. Leyland, A. Matthews and S. J. Dowey, Plasma Electrolysis For Surface Engineering, Surf. Coat. Technol., 1999, 122, 73-93.

8 M. P. Kamil, M. Kaseem and Y. G. Ko, Soft Plasma Electrolysis with Complex Ions for Optimizing Electrochemical Performance, Sci. Rep., 2017, 7, 4445844473.

9 D. Kim, D. Sung, J. Lee, Y. Kim and W. Chung, Composite Plasma Electrolytic Oxidation to Improve the Thermal Radiation Performance and Corrosion Resistance on an $\mathrm{Al}$ Substrate, Appl. Surf. Sci., 2015, 357, 1396-1402.

10 Y. S. Kim, H. W. Yang, K. R. Shin, Y. G. Ko and D. H. Shin, Heat Dissipation Properties of Oxide Layers Formed on 7075 Al Alloy via Plasma Electrolytic Oxidation, Surf. Coat. Technol., 2015, 269, 114-118.

11 Y. G. Ko, K. M. Lee and D. H. Shin, Effect of Ammonium Metavanadate on Surface Characteristics of Oxide Layer Formed on $\mathrm{Mg}$ Alloy via Plasma Electrolytic Oxidation, Surf. Coat. Technol., 2013, 236, 70-74.

12 I. J. Hwang, K. R. Shin, J. S. Lee, Y. G. Ko and D. H. Shin, Formation of Black Ceramic Layer on Aluminum Alloy by Plasma Electrolytic Oxidation in Electrolyte Containing $\mathrm{Na}_{2} \mathrm{WO}_{4}$, Mater. Trans., 2012, 53, 559-564.

13 S. Stojadinović, R. Vasilić, N. Radić, N. Tadić, P. Stefanov and B. Grbić, The Formation of Tungsten Doped $\mathrm{Al}_{2} \mathrm{O}_{3} / \mathrm{ZnO}$ Coatings on Aluminum by Plasma Electrolytic Oxidation and Their Application in Photocatalysis, Appl. Surf. Sci., 2016, 377, 37-43.

14 X. Wu, W. Qin, B. Cui, Z. Jiang and W. Lu, Black Ceramic Thermal Control Coating Prepared by Microarc Oxidation, Int. J. Appl. Ceram. Technol., 2007, 4, 269-275.

15 S. Somasundaram, A. M. Pillai, A. Rajendra and A. K. Sharma, High Emittance Black Nickel Coating on Copper Substrate for Space Applications, J. Alloys Compd., 2015, 643, 263-269.

16 A. R. Shashikala, A. K. Sharma and D. R. Bhandari, Solar Selective Black Nickel-Cobalt Coatings on Aluminum Alloys, Sol. Energy Mater. Sol. Cells, 2007, 91, 629-635.

17 F. I. Lizama-Tzec, J. D. Macías, M. A. Estrella-Gutiérrez, A. C. Cahue-López, O. Arés, R. de Coss, J. J. Alvarado-Gil and G. Oskam, Electrodeposition and Characterization of Nanostructured Black Nickel Selective Absorber Coatings for Solar-Thermal Energy Conversion, J. Mater. Sci.: Mater. Electron., 2015, 26, 5553-5561.

18 V. S. Rudneva, S. Wybornovc, I. V. Lukiyanchuka, T. Staedlerc, X. Jiang, A. Y. Ustinova and M. S. Vasilyevaa, Thermal behavior of $\mathrm{Ni}^{-}$and $\mathrm{Cu}$-containing plasma electrolytic oxide coatings on titanium, Appl. Surf. Sci., 2012, 258, 8667-8672.

19 Z. Yao, F. Jia, S. Tian, C. X. Lia, Z. Jiang and X. Bai, Microporous Ni-doped TiO2 film photocatalyst by plasma electrolytic oxidation, ACS Appl. Mater. Interfaces, 2010, 2, 2617-2622.

20 I. J. Hwang, K. M. Lee, B. Yoo and D. H. Shin, Characterization of nickel oxide layers on the AZ91 $\mathrm{Mg}$ alloys by plasma electrolytic oxidation, Mater. Sci. Forum, 2010, 654, 775-778.
21 A. Nominé, S. C. Troughton, G. Henrion and T. W. Clyne, High Speed Video Evidence for Localized Discharge Cascades During Plasma Electrolytic Oxidation, Surf. Coat. Technol., 2015, 269, 125-130.

22 C. S. Dunleavy, I. O. Golosnoy, J. A. Curran and T. W. Clyne, Characterisation of Discharge Events during Plasma Electrolytic Oxidation, Surf. Coat. Technol., 2009, 203, 3410-3419.

23 E. Matykina, A. Berkani, P. Skeldon and G. E. Thompson, Real-Time Imaging of Coating Growth during Plasma Electrolytic Oxidation of Titanium, Electrochim. Acta, 2007, 53, 1987-1994.

24 J. Yang, X. Lu, C. Blawert, S. Di and M. L. Zheludkevich, Microstructure and Corrosion Behavior of $\mathrm{Ca} / \mathrm{P}$ Coatings Prepared on Magnesium by Plasma Electrolytic Oxidation, Surf. Coat. Technol., 2017, 319, 359-369.

25 M. Kaseem, J. H. Kwon and Y. G. Ko, Modification of a porous oxide layer formed on an $\mathrm{Al}-\mathrm{Zn}-\mathrm{Mg}$ alloy via plasma electrolytic oxidation and post treatment using oxalate ions, $R S C$ Adv., 2016, 6, 107109-107113.

26 S. Ono, S. Moronuki, Y. Mori, A. Koshi, J. Liao and H. Asoh, Effect of Electrolyte Concentration on the Structure and Corrosion Resistance of Anodic Films Formed on Magnesium through Plasma Electrolytic Oxidation, Electrochim. Acta, 2017, 240, 415-423.

27 R. O. Hussein, X. Nie and D. O. Northwood, An investigation of ceramic coating growth mechanisms in plasma electrolytic oxidation (PEO) processing, Electrochim. Acta, 2013, 112, 111-119.

28 J. Jovovic, S. Stojadinović, N. M. Sisović and N. Konjević, Spectroscopic Study of Plasma During Electrolytic Oxidation Of Magnesium- and Aluminium-Alloy, J. Quant. Spectrosc. Radiat. Transfer, 2012, 113, 1928-1937.

29 Y. Cheng, Z. Xue, Q. Wang, X. Q. Wu, E. Matikyna, P. Skeldon and G. E. Thompson, New Findings On Properties Of Plasma Electrolytic Oxidation Coatings From Study Of An Al-Cu-Li Alloy, Electrochim. Acta, 2013, 107, 358-378.

30 S. C. Troughton, A. Nominé, A. V. Nominé, G. Henrion and T. W. Clyne, Synchronised electrical monitoring and high speed video of bubble growth associated with individual discharges during plasma electrolytic oxidation, Appl. Surf. Sci., 2015, 359, 405-411.

31 S. Fatimah, M. P. Kamil, J. H. Kwon, M. Kaseem and Y. G. Ko, Dual Incorporation of $\mathrm{SiO}_{2}$ and $\mathrm{ZrO}_{2}$ Nanoparticles into the Oxide Layer on $6061 \mathrm{Al}$ Alloy via Plasma Electrolytic Oxidation: Coating Structure and Corrosion Properties, $J$. Alloys Compd., 2017, 707, 358-364.

32 Y. G. Ko, S. Namgung and D. H. Shin, Correlation between $\mathrm{KOH}$ Concentration and Surface Properties of AZ91 Magnesium Alloy Coated by Plasma Electrolytic Oxidation, Surf. Coat. Technol., 2010, 205, 2525-2531.

33 K. R. Shin, Y. G. Ko and D. H. Shin, Effect of Electrolyte on Surface Properties of Pure Titanium Coated by Plasma Electrolytic Oxidation, J. Alloys Compd., 2011, 509, 478-481.

34 E. Matykina, R. Arrabal, P. Skeldon and G. E. Thompson, Investigation of The Growth Processes Of Coatings Formed 
By AC Plasma Electrolytic Oxidation of Aluminium, Electrochim. Acta, 2009, 54, 6767-6778.

35 X. Lu, M. Mohedano, C. Blawert, E. Matykina, R. Arrabal, K. U. Kainer and M. L. Zheludkevich, Plasma Electrolytic Oxidation Coatings with Particle Additions - A Review, Surf. Coat. Technol., 2016, 307, 1165-1182.

36 K. M. Lee, B. U. Lee, S. I. Yoon, E. S. Lee, B. Yoo and D. H. Shin, Evaluation of Plasma Temperature During Plasma Oxidation Processing of AZ91 Mg Alloy through Analysis of the Melting Behavior of Incorporated Particles, Electrochim. Acta, 2012, 67, 6-11.

37 D. Sreekanth, N. Rameshabu and K. Venkateswarlu, Effect of Various Additives on Morphology and Corrosion Behavior of Ceramic Coatings Developed on AZ31 Magnesium Alloy by Plasma Electrolytic Oxidation, Ceram. Int., 2012, 38, 46074615.

38 S. Moon and Y. Jeong, Generation Mechanism of Microdischarges during Plasma Electrolytic Oxidation of $\mathrm{Al}$ in Aqueous Solutions, Corros. Sci., 2009, 51, 1506-1512.

39 L. Chang, Growth regularity of ceramic coating on magnesium alloy by plasma electrolytic oxidation, J. Alloys Compd., 2009, 468, 462-465.

40 S. Fatimah, H. W. Yang, M. P. Kamil and Y. G. Ko, Control of Surface Plasma Discharge Considering The Crystalline Size of Al Substrate, Appl. Surf. Sci., 2018, DOI: 10.1016/ j.apsusc.2017.12.208.

41 P. Bruggerman and C. Leys, Non-Thermal Plasmas in and in Contact With Liquids, J. Phys. D: Appl. Phys., 2009, 42, 5300153029.

42 T. Belmonte, C. Noël, T. Gries, J. Martin and G. Henrion, Theoretical Background Of Optical Emission Spectroscopy for Analysis of Atmospheric Pressure Plasmas, Plasma Sources Sci. Technol., 2015, 24, 64003-64033.

43 R. O. Hussein, X. Nie, D. O. Northwood, A. L. Yerokhin and A. Matthews, Spectroscopic Study of Electrolytic Plasma and Discharging Behaviour During The Plasma Electrolytic Oxidation (PEO) Process, J. Phys. D: Appl. Phys., 2010, 43, 105203-105216.

44 M. Kaseem, M. P. Kamil, J. H. Kwon and Y. G. Ko, Effect of Sodium Benzoate on Corrosion Behavior of 6061 Al Alloy Processed by Plasma Electrolytic Oxidation, Surf. Coat. Technol., 2015, 283, 268-273.

45 H. S. Ryu, S. J. Mun, T. S. Lim, H. C. Kim, K. S. Shin and S. H. Hong, Microstructure Evolution during Plasma Electrolytic Oxidation and Its Effects on the Electrochemical Properties of AZ91D $\mathrm{Mg}$ Alloy, $J$. Electrochem. Soc., 2011, 158, 266-273.

46 H. Wang, F. Liu, X. Xiong, S. Ke, X. Zeng and P. Lin, Structure, Corrosion Resistance and In Vitro Bioactivity of $\mathrm{Ca}$ and $\mathrm{P}$ Containing TiO2 Coating Fabricated on NiTi Alloy by Plasma Electrolytic Oxidation, Appl. Surf. Sci., 2015, 356, 1234-1243.

47 D. S. Dalavi, R. S. Devan, R. S. Patil, Y. Ma, M. G. Kang, J. H. Kim and P. S. Patil, Electrochromic Properties of Dandelion Flower Like Nickel Oxide Thin Films, J. Mater. Chem. A, 2013, 1, 1035-1039.
48 A. P. Grosvenor, M. C. Biesinger, R. St. C. Smart and N. S. McIntyre, New Interpretations of XPS Spectra of Nickel Metal and Oxides, Surf. Sci., 2006, 600, 1771-1779.

49 X. Xiong, J. Zhang, J. Ma, X. Zeng, H. Qian and Y. Li, Fabrication of Porous Nickel (hydr)oxide Film with Rational Pore Size Distribution on Nickel Foam by Induction Heating Deposition for High-Performance Supercapacitors, Mater. Chem. Phys., 2016, 181, 1-6.

50 J. Yang, T. Fujigaya and N. Nakashima, Decorating Unoxidized-Carbon Nanotubes with Homogeneous Ni-Co Spinel Nanocrystals Show Superior Performance for Oxygen Evolution/reduction Reactions, Sci. Rep., 2017, 7, 45384-45393.

51 U. Singh, A. Banerjee, D. Mhamane, A. Suryawanshi, K. K. Upadhyay and S. Ogale, Surfactant Free Gram Scale Synthesis of Mesoporous $\mathrm{Ni}(\mathrm{OH})_{2}-\mathrm{R}-\mathrm{GO}$ Nanocomposite for High Rate Pseudocapacitor Application, RSC Adv., 2014, 4, 39875-39883.

52 Y. G. Ko, K. M. Lee and D. H. Shin, Electrochemical Corrosion Properties of AZ91 Mg Alloy via Plasma Electrolytic Oxidation and Subsequent Annealing, Mater. Trans., 2011, 52, 1697-1700.

53 B. Sasi and K. G. Gopchandran, Nanostructured Mesoporous Nickel Oxide Thin Films, Nanotechnology, 2007, 18, 115613.

54 B. Sasi, K. G. Gopchandran, P. K. Manoj, P. Koshy, P. P. Rao and V. K. Vaidyan, Preparation of Transparent and Semiconducting NiO Films, Vacuum, 2014, 68, 149-154.

55 Y. Wang, Q. Zhu and $\mathrm{H}$. Zhang, Fabrication of $\beta-\mathrm{Ni}(\mathrm{OH})_{2}$ and NiO Hollow Spheres by a Facile Template-Free Process, Chem. Commun., 2005, 41, 5231-5233.

56 L. Zhu, S. Shan, V. Petkov, W. Hu, A. Kroner, J. Zheng, C. Yu, N. Zhang, Y. Li, R. Luque, C.-J. Zhong, H. Ye, Z. Yang and B. H. Chen, Ruthenium-nickel-nickel hydroxide nanoparticles for room temperature catalytic hydrogenation, J. Mater. Chem. A, 2017, 5, 7869-7876.

57 D. Ma, G. Shi, H. Wang, Q. Zhang and Y. Li, Hierarchical NiO Microflake Films With High Coloration Efficiency, Cyclic Stability And Lower Power Consumption For Applications In a Complementary Electrochromic Devices, Nanoscale, 2013, 5, 4808-4815.

58 Y. Qi, H. Qi, J. Li and C. Lu, Synthesis, microstructures and UV-vis absorption properties of $\beta-\mathrm{Ni}(\mathrm{OH})_{2}$ nanoplates and NiO nanostructures, J. Cryst. Growth, 2008, 18, 4221-4225.

59 D. Ma, C. Lu, Z. Fang, W. Yan, L. Wei, Y. Ni and Z. Xu, Preparation of High Absorbance and High Emittance Coatings on 6061 Aluminum Alloy with A Pre-Deposition Method by Plasma Electrolytic Oxidation, Appl. Surf. Sci., 2016, 389, 874-881.

60 G. LeBlanc, E. Gizzie, S. Yang, D. E. Cliffel and G. K. Jennings, Photosystem I Protein Films at Electrode Surfaces for Solar Energy Conversion, Langmuir, 2014, 30, 10990-11001.

61 J. Seth, D. Nepak, V. R. Chaudhari and B. L. V. Prasad, Preparation of $\mathrm{MgO}$ Supported Platinum Nanoparticle catalyst using toluene dispersed platinum sol, Appl. Surf. Sci., 2017, 418, 87-91. 
62 M. M. Sundaram, A. Biswal, D. Mitchell, R. Jones and C. Fernandez, Correlation Among Physical and Electrochemical Behaviour of Nanostructured Electrolytic Manganese Dioxide From Leach Liquor and Synthetic For Aqueous Asymmetric Capacitor, Phys. Chem. Chem. Phys., 2016, 18, 4711-4720.

63 R. S. Borges, A. L. M. Reddy, M.-T. F. Rodrigues, H. Gullapalli, K. Balakrishnan, G. G. Silva and P. M. Ajayan, Supercapacitor Operating at 200 Degrees Celsius, Sci. Rep., 2013, 3, 2572-2578.

64 P. Axmann and O. Glemser, Nickel Hydroxide As a Matrix For Unusual Valencies; The Electrochemical Behavior of Metal(III)-Ion-Substituted Nickel Hydroxides of The Pyroaurite Type, J. Alloys Compd., 1997, 246, 232-241.

65 F. Peng, D. Wang, Y. Tian, H. Cao, Y. Qiao and X. Liu, Sealing the Pores of PEO Coating with Mg-Al Layered Double Hydroxide: Enhanced Corrosion Resistance, Sci. Rep., 2017, 7, 8167-8179.

66 H. Luo, Q. Cai, B. Wei, B. Yu, D. Li, J. He and Z. Liu, Effect of $\left(\mathrm{NaPO}_{3}\right)_{6}$ Concentrations on Corrosion Resistance of Plasma Electrolytic Oxidation Coatings Formed on AZ91D Magnesium Alloy, J. Alloys Compd., 2008, 464, 537-543.

$67 \mathrm{H}$. Li, S. Lu, X. Wu and W. Qin, Influence of $\mathrm{Zr}^{4+}$ Ions on Solar Absorbance and Emissivity of Coatings Formed on AZ31 Mg Alloy by Plasma Electrolytic Oxidation, Surf. Coat. Technol., 2015, 269, 220-227.

68 M. E. G. Lyons, R. L. Doyle, I. Godwin, M. O'Brien and L. Russel, Hydrous Nickel Oxide: Redox Switching and the Oxygen Evolution Reaction in Aqueous in Alkaline Solution, J. Electrochem. Soc., 2012, 159, 932-944.

69 K. M. Lee, K. R. Shin, S. Namgung, B. Yoo and D. H. Shin, Electrochemical Response of $\mathrm{ZrO}_{2}$-incorporated Oxide Layer on AZ91 Mg Alloy Processed by Plasma Electrolytic Oxidation, Surf. Coat. Technol., 2011, 205, 3779-3784.

70 X. Wu, W. Qin, B. Cui, Z. Jiang and W. Lu, Black Ceramic Thermal Control Coating Prepared by Microarc Oxidation, Int. J. Appl. Ceram. Technol., 2007, 4, 269-275.
71 L. Wang, J. Zhoua, J. Liang and J. Chen, Thermal Control Coatings on Magnesium Alloys Prepared by Plasma Electrolytic Oxidation, Appl. Surf. Sci., 2013, 280, 151-155.

72 M. Vedpathak, S. Basu and S. K. Kulkarni, Characterization of Nickel-Copper Multilayer and Copper Thin Film using Neutron Reflectivity Measurements, Appl. Surf. Sci., 1997, 115, 311-316.

73 H. Gonome, M. Baneshi, J. Okajima, A. Komiya and S. Maruyama, Controlling the Radiative Properties of Cool Black-Color Coatings Pigmented with CuO Submicron Particles, J. Quant. Spectrosc. Radiat. Transfer, 2014, 132, 90-98.

74 M. Aleksandrzak, P. Adamski, W. Kukułka, B. Zielinska and E. Mijowska, Effect of Graphene Thickness on Photocatalytic Activity of $\mathrm{TiO}_{2}$-Graphene Nanocomposites, Appl. Surf. Sci., 2015, 331, 193-199.

75 R. Riahi, L. Derbali, B. Ouertani and H. Ezzaouia, Temperature Dependence of Nickel Oxide Effect on the Optoelectronic Properties of Porous Silicon, Appl. Surf. Sci., 2017, 404, 34-39.

76 C. M. Chang, C. H. Wang, J. H. Hsu and J. C. Huang, Al-Ni$\mathrm{Y}-\mathrm{X}(\mathrm{X}=\mathrm{Cu}, \mathrm{Ta}, \mathrm{Zr})$ Metallic Glass Composite Thin Films for Broad-Band Uniform Reflectivity, Thin Solid Films, 2014, 571, 194-197.

77 S. Lu, W. Qin, X. Wu, X. Wang and G. Zhao, Effect of Fe3P Ions on The Thermal And Optical Properties of The Ceramic Coating Grown In-Situ on AZ31 Mg Alloy, Mater. Chem. Phys., 2012, 135, 58-62.

$78 \mathrm{H}$. Li, S. Lu, W. Qin and X. Wu, In-Situ Grown Mgo-Zno Ceramic Coating with High Thermal Emittance on $\mathrm{Mg}$ alloy by Plasma Electrolytic Oxidation, Acta Astronaut., 2017, 136, 230-235.

79 Z. Yao, Q. Shen, A. Niu, B. Hu and Z. Jiang, Preparation of High Emissivity and Low Absorbance Thermal Control Coatings on Ti Alloys by Plasma Electrolytic Oxidation, Surf. Coat. Technol., 2014, 242, 146-151. 